\title{
Louis Pasteur (1822-1895) Homenagem no centenário da sua morte
}

\author{
ANA CARNEIRO, A.M. NUNES DOS SANTOS*
}

$\mathrm{D}$ E ENTRE as personagens míticas da história da ciência, Pasteur é, sem sombra de dúvida, uma das mais exemplares. Desde há muito que ele é uma figura simbólica do nosso imaginário colectivo não só pelas suas contribuições científicas, cujo impacto no quotidiano nos é por demais familiar, mas também pelas características da sua personalidade, ou ainda pelos usos de que ambas foram alvo. A vida e obra de Pasteur suscitaram ao longo dos tempos narrações por vezes apaixonadas que se materializaram em múltiplas biografias ${ }^{1}$, histórias contadas às crianças e filmes que, fazendo apelo às emoções das várias audiências em termos muitas vezes melodramáticos, deram desta figura uma imagem frequentemente pouco verosímil, para não dizer completamente distorcida. Apesar da quantidade considerável de literatura a seu respeito, qualquer historiador da ciência verificará, facil e surpreendentemente ${ }^{2}$, a ausência de uma biografia científica de Pasteur exaustiva e profissionalmente elaborada ${ }^{3}$. A nossa contribuição no centenário da sua morte, ocorrida em 28 de Setembro de 1895 será, tão somente, uma tentativa de divulgar aspectos da vida e obra de Pasteur, porventura menos conhecidos.

\section{PASTEUR, ALGUNS ASPECTOS DA SUA OBRA CIENTÍFICA}

A investigação científica de Pasteur abrangeu uma gama vasta de tópicos que só na aparência poderão parecer desconexos, mas que na realidade revelam uma grande unidade metodológica. As implicações dos seus estudos são igualmente extensas, dado o seu impacto quer ao nível da investigação fundamental quer em campos como a bioquímica, a microbiologia, a medicina, a veterinária, a higiene e a produção industrial de bens alimentares. Porém, por uma questão de comodidade a sua obra poderá ser, ainda que sumariamente, resumida do modo seguinte ${ }^{4}$ :

1847-1857 - Cristalografia: actividade óptica e assimetria cristalina;

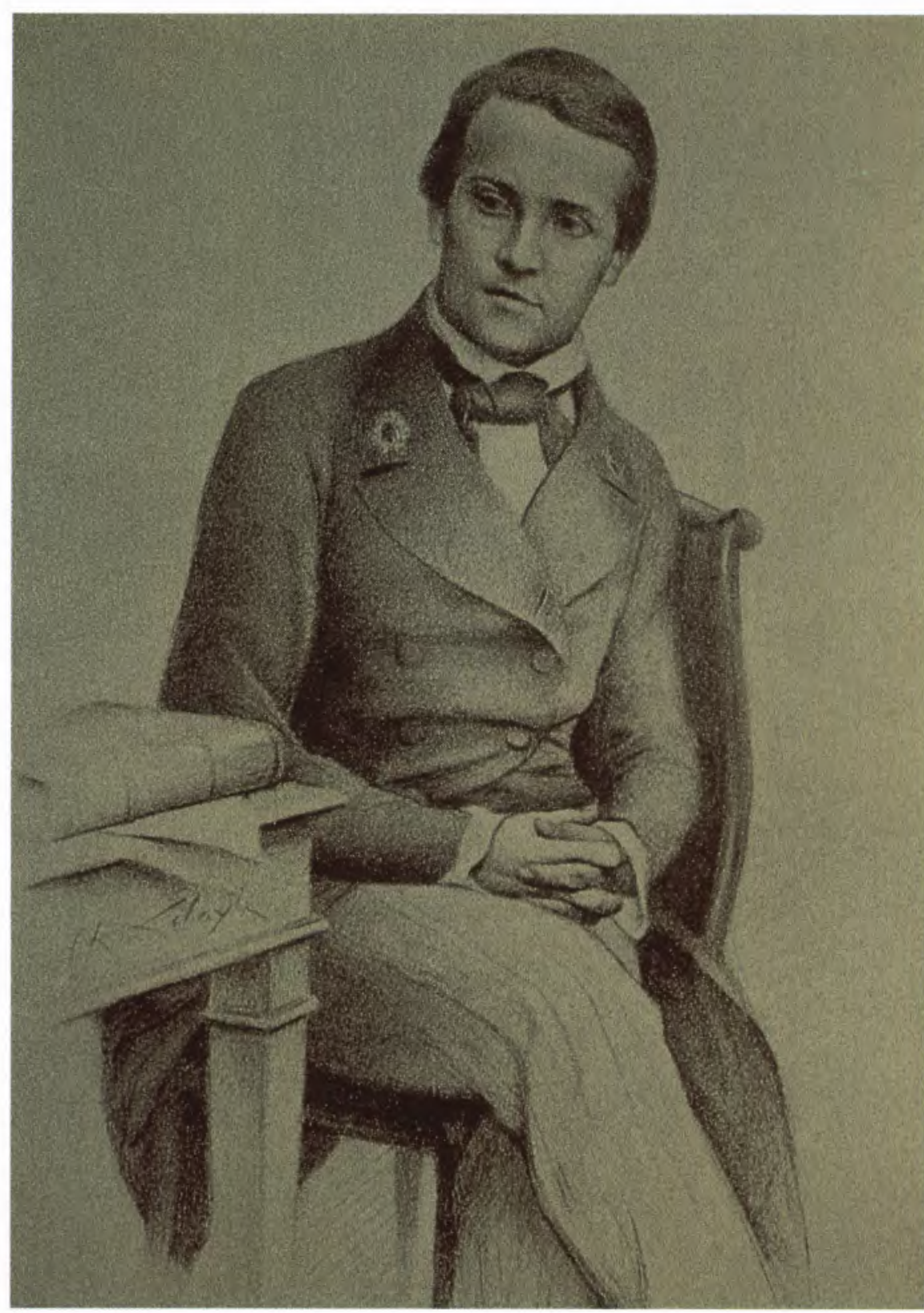

1857-1865 - Fermentação e geração espontânea; estudos aplicados aos casos do vinagre e do vinho;

1865-1870 - Doenças dos bichos da seda: pébrine e flacherie,

1871-1876 - Investigação aplicada às cervejas; controvérsias a propósito da fermentação e da geração espontânea;

1877-1895 - Etiologia e profilaxia de doenças infecciosas: carbúnculo, cólera das aves, erisipela dos suínos e raiva.
Se bem que Pasteur tenha avançado com ideias imaginativas e até mesmo ousadas para a ciência do seu tempo, o seu trabalho caracterizou-se, essencialmente, por uma grande clarividência, uma intuição experimental invulgar, uma enorme capacidade de trabalho e por uma grande dose de obstinação. Porém, os seus contributos para a ciência fundamental, sendo de importância e significado inestimáveis, são menos revolucionárias do que a sua fama tem 
feito crer. Ironicamente, as suas contribuições mais originais são também as menos conhecidas, até porque localizando-se no começo da sua carreira foram divulgadas de modo menos espectacular.

Assim, em 1847, inspirando-se nos trabalhos do mineralogista Gabriel Delafosse (1796-1878), do cristalógrafo Jean-Baptiste Biot (17741862) e do químico Auguste Laurent (1808-1853), Pasteur iniciou uma série de pesquisas inovadoras 5 sobre a relação entre a actividade óptica, a estrutura cristalina, e a composição química em compostos orgânicos. mais especificamente, nos ácidos tartárico e paratartárico. Estas investigações, visando em última análise o estabelecimento de uma relação entre actividade óptica e vida, originaram e forneceram várias metodologias para uma abordagem completamente nova do estudo da estrutura química e da composição. Pasteur abriu assim, por um lado, um novo campo de investigação em que os seus trabalhos constituiram-se como alicerces fundamentais da estereoquímica. Nomeadamente, o trabalho de Joseph-Achilles Le Bel (1847-1930) sobre o carbono assimétrico, publicado em 18746, assentou em boa parte nestas investigações. Por outro, Pasteur era dissidente da ideia que surgiu nessa altura de unificar a química, unificação essa consubstanciada na célebre frase de Adolphe Wurtz (1817-1884), there is but one chemistry $^{7}$, que se referia, fundamentalmente, a uma união entre a química orgânica (o comportamento dos compostos orgânicos não podiam ser mais visualizados como misteriosos ou dependentes de agentes vitais) e a química inorgânica. Inicialmente, a síntese da ureia efectuada por Friedrich Wöhler (1800-1882) tornara-se no dizer de August Wilhelm von Hofmann (1818-1892), o gospel of a new unified chemistry e as sínteses directas realizadas por Marcellin Berthelot (1827-1907) ajudaram a cimentar aquela aliança. Pasteur opunha-se a uma unificação da química. Contudo, para ele esta questão não se colocava tanto em termos da dicotomia entre inorgânico e orgânico mas antes entre natural e artificial. Assim, Pasteur considerava a existência de uma diferença qualitativa essencial entre os compostos orgânicos preparados artificialmente no laboratório, fosse qual fosse a via, e esses mesmos compostos obtidos por processos naturais nos seres vivos. Na verdade, ele insistia que a distinção mais profunda entre os produtos formados sob a influência da vida e os restantes radicava no facto dos produtos artificiais não terem assimetria molecular8. Assim, a química dividir-se-ia em três ramos: a química orgânica, a química inorgânica e a química dos seres organizados, correntemente denominada química fisiológica ou biológica como the chamou Wurtz. O problema de uma unificação se bem que defendida pela grande maioria dos químicos do séc. XIX, tinha nuances importantes: para uns tratava-se de subordinar a química orgânica às leis da química inorgânica como por exemplo, defendia Berthelot; para outros tratava-se de subordinar a química inorgânica aos princípios da química orgânica tal como advogava Wurtz. Quanto à química fisiológica ou biológica, a questão de uma unificação era ainda mais complexa por via não só da própria complexidade dos fenómenos biológicos como também da já referida dicotomia natu$\mathrm{ral} /$ artificial.

Não obstante, não se quedando no desenvolvimento dos seus primeiros trabalhos, da área da cristalografia e da química estrutural Pasteur, que se considerava ele próprio um químico ${ }^{9}$, passou para assuntos mais controversos como a fermentação e a geração espontânea. Assim. viria a empenhar-se profundamente na formulação de uma teoria da fermentação e no desacreditar da teoria da geração espontânea, envolvendo-se em duas conhecidas controvérsias, a da fermentação entre 1871 e 1876 e a da geração espontânea entre 1871 e 1879 . No que se refere à polémica da fermentação travada com Justus von Liebig (1803-1873), o pomo da discórdia residia no facto de Liebig sustentar que não era ne- cessária a presença de um microrganismo para que a fermentação ocorresse (no caso presente da fermentação acética tratava-se da Mycoderma aceti). Pasteur, ao contrário, considerava essa presença essencial ${ }^{10}$. A resolução desta polémica, isto é, a aceitação de que a fermentação se explica pela acção catalítica de enzimas segregados por organismos vivos $\mathrm{e}$ que pode ocorrer na ausência destes, veio a ser avançada por Eduard Buchner (1860-1917), em 1897. Buchner no decurso dos seus trabaIhos sobre imunologia conseguiu isolar um fermento solúvel em álcool, isto é um extracto livre de células com actividade enzimática.

Em 1859, Félix Pouchet (18001872) publicava uma obra intitulada Hétérogenie, onde se relatam inúmeras experiências em abono da ocorrência de geração espontânea. Aliás desde tempos mais remotos parecia, para o observador incauto e casual, que as moscas ou pelo menos as larvas podiam surgir de matéria em putrefacção. Contudo, também parecia surgir matéria-viva da própria água sujeita a destilação. Havia assim uma enorme confusão sobre a possibilidade de geração espontânea. Porém, na sequência da publicação do livro de Pouchet, a Académie des Sciences decidiu atribuir um prémio a quem conseguisse provar ou infirmar definitivamente a existência daquele fenómeno. Em 1862, Pasteur demonstra pelas suas já célebres experiências ${ }^{11}$ que os micróbios pululam não só no ar e nas poeiras, mas também nas mãos e nos instrumentos e equipamentos experimentais. Todos os microrganismos resultariam, na realidade, da contaminação das culturas por germes vindos do exterior.

Em nenhuma circunstância se pode afirmar que os seres microscópicos surjam sem a presença de um germe, sem um progenitor semelhante a eles próprios. Aqueles que afirmam isso estão enganados pelas ilusōes, pelas experiências mal conduzidas, logradas por erros que não compreendem ou que não sabem evitar12. 
Convém realçar, no entanto, que nas misturas utilizadas por Pasteur nas suas experiências ${ }^{13}$ não existiam microrganismos resistentes ao calor, o que decerto facilitou a afirmação tão cabal da sua teoria ${ }^{14}$, relativamente ao seu oponente Pouchet.

Todavia, se Pasteur se empenhou mais do que ninguém no sentido de promover uma teoria da fermentação e de desacreditar a teoria da geração espontânea, isto não se deveu a uma intrínseca originalidade conceptual, mas antes a um enorme engenho experimental e a uma verdadeira inclinação para a polémica ${ }^{15}$ onde se revelava devastador e por vezes cruel. Pasteur mostrou-se extremamente combativo, chegando a invocar argumentos pouco científicos como, por exemplo, os de natureza nacionalista ${ }^{16}$ para ajuizar da "verdade" das teorias dos adversários. Por outro lado, a sua tendência para a auto-publicidade, a que se juntou um reconhecimento intuitivo da importância de persuadir e conquistar a concordância da comunidade envolvente, mostraram-se decisivos na afirmação das suas teorias. Pasteur publicitava regularmente os seus trabalhos científicos e as suas posições ideológicas através de artigos publicados na Revue Scientifique e outras, o que lhe permitia divulgar o seu trabalho por forma a conquistar adeptos. Nomeadamente, a polémica da geração espontânea não se confinou à comunidade científica, sendo seguida com toda a atenção por um público mais vasto dadas as alegadas implicações no domínio religioso, filosófico e até político, no quadro do debate que corria entre materialismo e espiritualismo. Os resultados de Pouchet foram convertidos em argumentos a favor do materialismo, do evolucionismo e do radicalismo político, enquanto os de Pasteur foram postos ao seviço do espiritualismo, da visão bíblica da criação e do conservadorismo político. Pasteur considerava que a doutrina da geração espontânea tal como o materialismo punha em causa o conceito de um Deus criador, embora insistisse que efectuou as suas experiências sem ideias preconcebidas e que teria decidido a favor da geração espontânea caso os resultados experimentais assim o exigissem ${ }^{17}$.

Mas além da propaganda escrita destinada a inflamar grandes audiências, as visitas ao seu laboratório promovidas entre os membros da família imperial18, os industriais, os políticos, os jornalistas e os membros do governo do Segundo Império, a quem maravilhava com o microscópio revelando o mundo do infinitamente pequeno ${ }^{19}$, grangearam-lhe apoios inestimáveis.

Porém, se no caso da microbiologia as contribuições de Pasteur foram primordiais, nomeadamente no que respeita à relação entre microrganismos e o seu meio ambiente, rapidamente transferiu este seu interesse pela investigação fundamental para a resolução de questões de ordem prática: produção do vinho, do vinagre e da cerveja; etiologia e profilaxia de doenças infecciosas. Se esta mudança de interesse é, obviamente, em si mesma perfeitamente legítima, as razões que a determinaram (se bem que igualmente legítimas) são complexas.

Do ponto de vista da lógica interna das suas investigações, o interesse de Pasteur na resolução de problemas de ordem prática terá evoluído naturalmente da sua investigação fundamental. Em particular, a seu trabalho na área da fermentação destinada à formulação de uma teoria biológica deste fenómeno continha em si um potencial de aplicação à indústria. Ele próprio insistiu na existência de uma evolução natural da cristalografia à patologia, passando pela fermentação, progressão essa por ele vista como inevitável20. Porém, numa fase avançada da sua vida, Pasteur terá lamentado o facto de ter abandonado os tópicos de pesquisa do início de carreira a favor da aplicação, em especial o não ter explorado completamente as relações entre assimetria e vida. No entanto, a questão relativa a esta mudança da investigação fundamental para a aplicação, cujos resultados se reper- cutiram em tantos domínios, deverá contemplar não só as suas motivações pessoais como também um contexto histórico mais alargado.

Assim, uma primeira razão terá sido a concordância de Pasteur com as políticas do Segundo Império. De facto, Napoleão III estava interessado no desenvolvimento da ciência aplicada e daí que ele próprio se tenha tornado patrono de Pasteur ${ }^{21}$, atribuindo às suas investigações somas consideráveis, segundo os padrões da época. Por outro lado, o prestigiado e entretanto poderoso químico JeanBaptiste André Dumas (1800-1884), de quem Pasteur se considerava discípulo, era um patrono de grande eficácia, sendo um intermediário decisivo na obtenção de financiamentos tanto de Napoleão III, como da Académie des Sciences de Paris de que era Secretário vitalício, como ainda do governo, na sua qualidade de Senador e posteriormente de Ministro da Agricultura.

A correspondência de Pasteur dá conta destes e de outros motivos para a sua mudança de interesses. Todavia, estes tiveram a ver não só com a conjuntura política de que era um acérrimo defensor como, também, das características da sua maneira de ser. A ambição e o desejo de fama e reconhecimento público e do Império a que já aludimos 22; o seu desejo frequentemente expresso de servir a França para que esta atingisse a superioridade científica no conjunto das nações e, em particular, relativamente ao Estados Germâni$\cos ^{23}$; a sua obsessão com a segurança material, especialmente, no que se refere ao trabalho e à sua família, terão constituído razões fortes para a mudança de orientação operada na sua carreira de investigador. Não se deve esquecer também o ambiente altamente competitivo da cena científica parisiense ${ }^{24}$ dos meados do século XIX, onde os apoios do cristalógrafo Biot a princípio, depois de Dumas e, mais tarde, da classe dirigente se revelaram fundamentais para assegurar a sua carreira científica. 


\section{PASTEUR E OS SEUS DISCÍPULOS}

Uma das dimensões mais aliciantes do trabalho científico foi, no séc. XIX (e porventura ainda hoje), a possibilidade de formar jovens investigadores, deixando-lhes um legado científico passível de posterior exploração e desenvolvimento, sem afastar a possibilidade de inovação criativa no plano individual. Daí que durante todo o século passado pululassem um pouco por toda Europa, especialmente nos Estados Germânicos, na Grã-Bretanha, no Império Russo e em França escolas de investigação cujas origens terão emergido no período romântico, nomeadamente como resultado dos princípios subjacentes à reforma das universidades alemãs, de que foram arautos Naturphilosophen como Schelling com a sua obra Vorlesung über die Method des Akademischen Studiums (1803), Fichte, Schleiermacher e os irmãos von Humboldt 25 .

Pasteur não foi excepção neste movimento de implantação de escolas de investigação em França na segunda metade do século, de que o seu mestre Dumas havia sido pioneiro em Paris, seguindo o exemplo de Liebig em Giessen. Todavia, a maneira como Pasteur concebeu a forma de fazer escola foi sui generis relativamente aos seus contemporâneos, se bem que enquadrada, em muitos aspectos, numa tradição de um certo funcionalismo público que veio a caracterizar de forma progressivamente mais marcante a formação de investigadores na escolas de investigação francesas da época 26 .

Os trabalhos de Pasteur na sua variedade tiveram como traço dominante o facto de ele iniciar áreas inexploradas que depois eram desenvolvidas pelos seus discípulos, abrindo-se desta forma caminho a novos ramos do conhecimento científico. Assim, tomemos como exemplo o trabalho do seu discípulo Emile Duclaux (1840-1904) que com Pasteur trabalhou nas investigações sobre as doenças dos bichos da seda, a raiva e sobre a cerveja. Será no capítulo das fermentações e das suas aplicações práticas, que a experiência adquirida por Duclaux se tornou mais produtiva levando-o, mais tarde, a dedicar-se ao estudo das diastases, fundamental para a emergência da enzimologia. Por outro lado, Emile Roux (18531933), juntamente com Charles Chamberland(1851-1908) e Louis Thuillier (1856-1883) trabalharam com Pasteur sobre o carbúnculo e na atenuação de vírus o que conduziu à preparação de vacinas, nomeadamente, a da raiva. Posteriormente, Roux dedicou-se à prevenção da difteria que culminaria com a preparação do soro anti-diftérico em 1894. Chamberland, por seu turno, enveredou pelas aplicações da microbiologia à higiene, aperfeiçoando métodos de esterilização de que se destaca o autoclave, e vários outros relacionados com o isolamento de microrganismos e toxinas até então desconhecidos, através do uso de filtros especiais por ele concebidos.

Porém, no que se refere ao recrutamento de discípulos, Pasteur fê-lo não tanto porque lhe interessasse formar jovens investigadores, mas por razões de ordem mais pragmática. Aparentemente, o recrutamento de assistentes resultou mais da necessidade de colmatar as suas próprias "limitações". Estas relacionavam-se com a paralisia do lado esquerdo resultante do acidente cerebral que o acometera em 1860 , impossibilitando-o de executar a maior parte do trabalho experimental. Pasteur limitava-se assim a conceber e a dirigir as experiências que eram executadas pelos seus discípulos, mas controladas por ele através de uma vigilância apertada e por vezes obsessiva. Como testemunha o seu sobrinho e discípulo André Loir:

Ele [Pasteur] gostava de estar sozinho no laboratório e nunca falava do propósito que tinha em mente.... Escrevia em pequenas fichas as experiências que queria ver realizadas e, depois, sem explicar nada aos assistentes pedia-lhes simplesmente que as realizassem 27

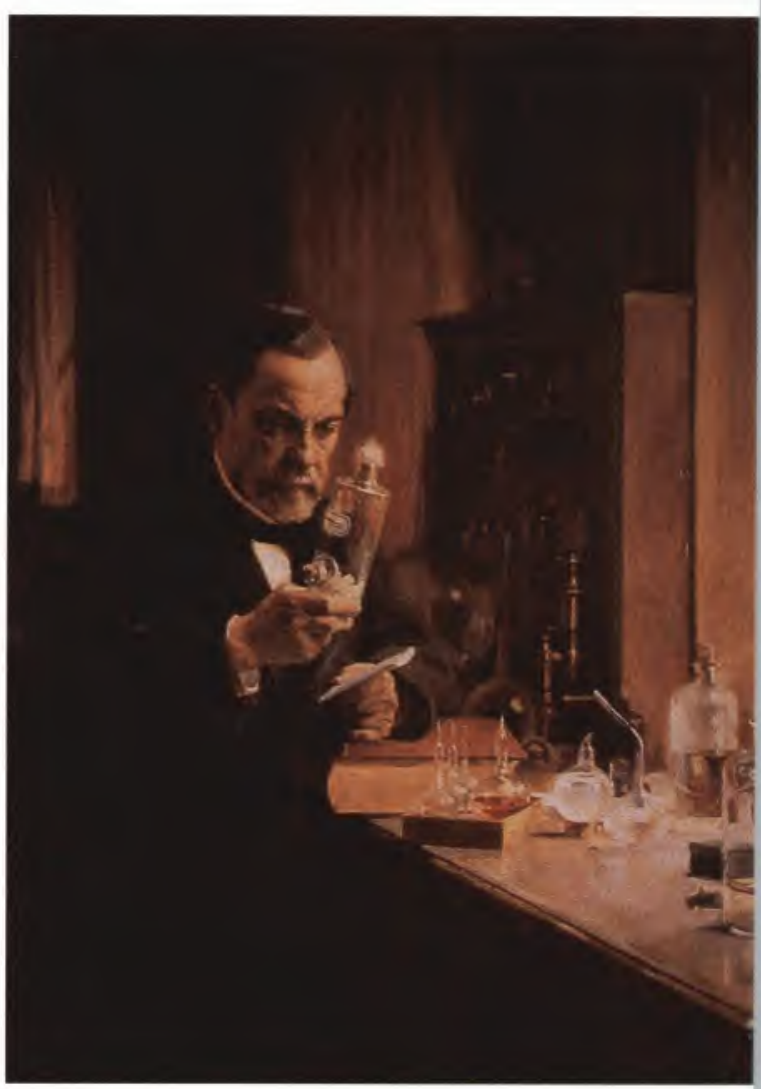

Além disso, o ambiente no laboratório era carregado, pois le maître ne savait pas rire 28 . O silêncio era regra de ouro ${ }^{29}$, o asseio absolutamente escrupuloso, e qualquer sinal de conforto era muito mal visto por Pasteur ${ }^{30}$.

Em 1877, com as suas incursões em domínios tradicionalmente do foro da medicina, Pasteur tinha não só de enfrentar a sua paralisia parcial como ainda a sua ignorância em matérias de índole médica e veterinária, juntamente com a sua repulsa em relação à vivissecção. Daí que, além de recrutar licenciados pela Ecole Normale (os Normaliens) onde leccionava, passasse também a recrutar clínicos, principalmente por uma questão de credibilidade face à comunidade médica. No entanto, Pasteur não treinou directamente senão um número muito reduzido dos seus discípulos. $\mathrm{Na}$ verdade, interessava-se pouco por eles o que terá levado alguns a abandonar cedo o laboratório devido à distância e indiferença reinante. 
Assim, as tarefas de recrutamento, a assistência no trabalho de investigação, a transmissão dos métodos de pesquisa e dos valores a ela associados, bem como a administração dos orçamentos devido à repulsa pelo dinheiro que Pasteur alegava, estavam a cargo dos seus discípulos mais chegados Duclaux, um Normalien, e Roux, um médico ${ }^{31}$. Com efeito, eles foram os sólidos pilares que sustentaram a execução da empresa científica de Pasteur, que culminaria em termos institucionais com a criação do Institut Pasteur em 1888.

Pasteur era obsessivo quanto à propriedade intelectual e quanto ao estabelecimento de prioridade relativamente às suas descobertas. Talvez por isso não surpreenda o facto de as publicações dos seus discípulos mais directos, em particular Duclaux e Roux, serem em número tão escasso, se atendermos ao facto de terem desde cedo trabalhado em estreita colaboração com o mestre, enquanto este foi vivo. Assim, no que se refere a Duclaux, este nunca publicou artigos em co-autoria com o mestre, o que sugere que Pasteur se possa ter apropriado do trabalho do seu discípulo. Quanto a Roux, só escreveu um pequeno número de artigos a título individual antes de 1890 e alguns outros em co-autoria com Pasteur. Estes últimos parecem ter sido ditados pela necessidade do mestre se afirmar perante a comunidade médica, na tentativa de afastar eventuais motivos de suspeição. A prática de Pasteur relativamente à publicação dos trabalhos dos seus discípulos enquadra-se, em certa medida, na tradição francesa, sendo corrente que a maior parte dos patron subscrevesse, enquanto co-autores, os artigos dos seus assistentes e discípulos, ainda que para eles pudessem não ter contribuído directamente ${ }^{32}$.

Apesar da postura distante e algo prepotente de Pasteur face aos seus assistentes e continuadores mais directos, ela nunca mereceu da parte destes reparos directos. Duclaux afirmava:
Julgo que jamais uma comunidade tão unida tenha, deste modo, rodeado um chefe. Nós não estávamos ao corrente do que se passava na cabeça de Pasteur, porque ele guardava para si próprio projectos e ideias, mas adivinhávamos ou pensávamos que adivinhávamos e isto era suficiente para nos manter interessados ${ }^{33}$.

Talvez a sua conhecida intolerância face à crítica ${ }^{34}$ por um lado, mas também a ideologia associada tanto ao positivismo como ao catolicismo, inibisse aqueles que o rodeavam. O confronto entre as correntes positivista e católica atravessou a sociedade francesa do Segundo Império à Terceira Republica, mas a ideologia de ambas estava talhada para despertar nos savants uma veneração subserviente aos mestres, bem ainda como o sentido de esforço abnegado e apagamento pessoal de que deveria revestir-se o trabalho científico ${ }^{35}$.

\section{PASTEUR, O ENSINO SUPERIOR E A INVESTIGAÇÃO CIENTÍFICA}

Pasteur foi considerado pelos seus alunos um excelente professor, sendo as suas aulas criteriosamente preparadas e os assuntos expostos de forma clara e bem articulada. Na prestigiosa Ecole Normale teve um papel importante como administrador e director de estudos científicos. Propôs e desencadeou reformas estruturais, criando um periódico científico os Annales scientifiques de l'Ecole normale supérieure, destinado a publicar resultados decorrentes da investigação e elevou os padrões e a reputação científica da escola por forma acicatar a competição com a outra grand école, a Ecole Polytechnique. Todavia, a inflexibilidade e autoritarismo nas suas relações, especialmente com os estudantes com quem lidava de forma por vezes arbitrária, levou a que fosse convidado a demitir-se, em 186736.

No entanto, Pasteur envolveu-se com grande determinação nas discussões sobre o ensino universitário e a investigação científica. Em particular, bateu-se para que fossem dados meios para a dotação de laboratórios de investigação, mas também pelo fim de certas práticas no ensino superior tão típicas do sistema francês. Assim, opunha-se ao cumul e à suppléance ${ }^{37}$ que considerava nocivos. O cumul era a forma pela qual os professores acumulavam funções docentes em vários estabelecimentos de ensino superior, não só porque eram mal pagos mas também porque lhes permitia alargar as suas esferas de influência. A esta prática associava-se a suppléance através da qual os professores titulares delegavam nos seus protégés funções docentes mediante o pagamento de uma fracção do seu salário, assegurando assim um maior controlo e influência no quadro da política académica. As situações de suppléance podiam arrastar-se por largos anos 38 dada a impossiblidade dos titulares poderem desempenhar as suas múltiplas funções docentes, a que frequentemente vinham juntar-se cargos políticos $\mathrm{e}$ administrativos. Com este sistema também se comprometia a possibilidade de existirem laboratórios de investigação produtivos nas várias instituições de ensino superior, por indisponibilidade dos docentes tutelares, ao mesmo tempo que se anulavam quaisquer hipóteses de renovação.

Se bem que durante o Segundo Império muitos savants se queixassem publicamente do desprezo a que as autoridades francesas tinham alegadamente votado a ciência, apontando frequentemente, num misto de fascínio e revolta ${ }^{39}$ os Estados Germânicos como o exemplo a seguir, Pasteur foi dos que protestou mais veementemente a favor de apoios oficiais, contra a possibilidade de uma supremacia científica alemã, tanto antes como depois da Guerra Franco-Prussiana (1870-1872) da qual a França saiu derrotada 40 .

No que se refere aos laboratórios de investigação, a situação em França estava longe de ser a desejável, pelo que ficou célebre a frase de Claude Bernard (1813-1887) quan- 
do afirmou que les laboratoires sont les tombeaux des savants. Além de escassos, não possuiam as condições adequadas nem verbas específicas para custear a investigação. A sua existência estava à mercê de jogos de influência e dos favores que os seus directores conseguiam, conforme a sua mobilidade na cena política e académica. Vulgarmente, eram instalados em qualquer edifício disponível, normalmente desajustado do fim em vista e, frequentemente, não dispunham de uma infra-estrutura mínima, pelo que a improvisação reinava.

Vários foram pois os que se insurgiram contra este estado de coisas, e houve mesmo quem defendesse que, no quadro de uma autonomia universitária de inspiração germânica ${ }^{41}$ que se pretendia ver implantada, fossem criados institutos de investigação expressamente construídos e equipados, gozando eles próprios de certa autonomia face à própria universidade a que ficariam liga$\operatorname{dos}^{42}$.

No contexto destes debates no seio da comunidade científica francesa, Pasteur advogou em diversas ocasiões a construção de laboratórios de investigação, incitando os seus concidadãos a uma atitude reivindicativa:

Interessem-se, é a minha palavra de ordem, por estes locais sagrados a que damos o nome expressivo de laboratórios. Exijam que eles sejam multiplicados e ornados: eles são os templos do futuro, da riqueza e do bem-estar ${ }^{43}$.

Como ele afirmava em 1868 , era preciso mobilizar a opinião públi$\mathrm{ca}$, porque nas suas palavras

É preciso trabalhar por todos os meios possíveis para assegurar, num futuro próximo, a superioridade científica da França. ${ }^{44}$

Todavia, no quadro da época e em termos pessoais, Pasteur não teria muitas razões para se lamentar, especialmente desde que optou pela aplicação da ciência a proble- mas práticos. De facto, quase sempre obteve as verbas que solicitou; foi-lhe concedido um novo laboratório dotado de um orçamento considerável para investigação; foramlhe atribuídas verbas adicionais para pessoal; foi-lhe dada uma pensão do estado para si próprio; foram-lhe concedidos transportes gratuitos nos caminhos-de-ferro para si e para os seus assistentes. Além disso, mercê do seu espírito competitivo e da forma como soube publicitar os seus trabalhos e a sua importância, usufruiu também de fundos que obteve de sociedades privadas e de governos estrangeiros.

Deste modo, todos estes dados nos permitem concluir que, no quadro da época, a sua situação era invejável quando comparada à dos seus colegas franceses mais destacados, embora fosse comparável àquela que era outorgada aos homens de ciência nas universidades alemãs. Sendo assim, a sua exagerada insistência na defesa de que os propósitos do seu trabalho eram os de um savant desinteressado e motivado pelo amor à ciência e à Pátria têm, inevitávelmente, de ser ponderados tendo em conta a conjuntura dos restantes elementos da comunidade científica parisiense da época, e ainda a ambição pessoal e o oportunismo com que, por vezes, se revestiram os meios de que Pasteur se serviu no intuito de atingir os seus fins, pretensa e insistentemente apresentados por ele e por certos biógrafos como destituídos de qualquer interesse pessoal.

Apesar de todas estas lutas em que Pasteur e os seus colegas se empenharam, a situação em França pouco se alterou nos anos subsequentes. Embora em 1868, o Ministro da Educação, Victor Duruy, tenha criado a Ecole Pratique des Hautes Etudes, esta não passou de uma supra-estrutura. No fundo, a EPHE resumiu-se a um instrumento burocrático que se limitou a enquadrar oficialmente os laboratórios já existentes. Mesmo no regime republicano instalado após o conflito com a Prússia, o estado de coisas pouco se modificou: a burocracia, o excessivo centralismo, o espírito de funcionalismo e o tráfico de influências permaneceram.

Pasteur viria, no entanto, a criar uma instituição à medida das suas aspirações. Fundado já durante a Terceira República, regime a que Pasteur era completamente avesso de forma um tanto primária, o Instituto Pasteur foi construído mercê duma subscrição pública nacional e de apoios internacionais. Dotado de laboratórios especializados e sem fins lucrativos, o Instituto Pasteur foi um veículo fundamental na difusão dos métodos de Pasteur, pois aí se formou uma plêiade de técnicos e investigadores que se espalharam pelo mundo inteiro, nas suas várias sucursais. Na sua acção de enorme relevância, o Instituto Pasteur materializou o espírito de quase missionação e de combate tão peculiar a Pasteur (aliás, eloquentemente demonstrado por Bruno Latour ${ }^{45}$ ), encaixando-se simultaneamente na ideia de mission civilisatrice tão cara à própria França.

Devido à sua incompatibilidade com o regime republicano, Pasteur afastou a possibilidade de vir a ser sepultado no emblemático Panthéon (onde aliás o seu colega Marcellin Berthelot viria a ser "canonizado" pelo regime), expressando o desejo de jazer para a eternidade na cripta do Instituto a que dera o seu nome. É lá que se encontram os seus restos mortais, num túmulo rodeado por quatro anjos esculpidos de brancura imaculada simbolizando a Fé, a Esperança, a Caridade e a Ciência, valores de que ele próprio se fez símbolo 46 .

\footnotetext{
* Secção de História e Filosofia da Ciência Faculdade de Ciências e Tecnologia Universidade Nova de Lisboa
} 


\section{NOTAS}

1 As obras de carácter biográfico mais relevantes do ponto de vista histórico são: R. Vallery-Radot, La vie de Pasteur (Paris, 1900); E. Duclaux, Pasteur. Histoire d'un esprit (Paris, 1896); R. Dubos, Louis Pasteur Free Lance of Sceince (Boston, 1950); H. Cuny, Louis Pasteur. L'homme et ses théories (Paris, 1963); J. Nicolle, Pasteur: sa vie, sa méthode, ses découvertes (Paris, 1969). (Nota suplementar: Após a leitura do artigo, acaba de sair a obra de Gerald Geison intitulada The private science of Louis Pasteur, publicado pela Princeton University Press.)

2 Também neste aspecto a figura de Pasteur é exemplar, pois dificilmente se encontraria um acervo de fontes históricas mais completo e melhor conservado.

${ }^{3}$ No entanto, de entre os estudos parcelares recentes bas tante estimulantes sảo de destacar: J. K Crellin, "Airborne particles and the germ theory, 1860-1880", Medical History, 10 (1966), 49-60; I. Farley; G. Geison, "Science, Politics and Spontaneous Generation in Nineteenth Century France", Bulletin of the History of Medicine, 48 (1974); G. Vandervliet, Microbiology and the Spontaneous Generation Debate During the 1870 s (Lawrence, 1971);:B. Latour, The Pasteurization of France, (Cambridge, Mass., 1988).

${ }^{4}$ G. Geison, Artigo Louis Pasteur, in C. Gillispie, (edit.), Dictionary of Scientific Biography, (N. York, 1970-1980), 10, 350-416.

5 Os principais trabalhos de Pasteur nesta área foram publicados entre 1848 e 1860 nos Annales de Chimie e nos Comptes Rendus da Académie des Sciences. As teorias de Pasteur sobre a assimetria molecular e actividade óptica na sua forma final estão sumarizadas nas "Recherches sur la dissymétrie moléculaire des produits organiques naturels", in Leçons de chimie professées en 1860, (Paris. 1861), 1-48.

${ }^{6} \mathrm{~A}$ teoria do carbono assimétrico de Le Bel foi formulada quase em simultâneo e independentemente da teoria de Jacobus van't Hoff (1850-1903). Como ambos afirmaram, apesar de terem sido contemporâneos no laboratório de investigação de Adolphe Wurtz, na Ecole de Médecine, jamais terão discutido este assunto. Na verdade, as origens da formulação de Le Bel inserem-se na tradição dos estudos de Pasteur, e as do seu colega holandês mais na teoria estrutural dos compostos orgânicos de Kekulé. A. Carneiro, The Research School of Chemistry of Adolphe Wurtz, Paris, 1853-1884, (Tese de doutoramento, Univer. sidade de Kent, Canterbury, 1992), 191; I. A. Le Bel, "Sur les relations qui existent entre les formules atomiques des corps et le pouvoir rotatoire", Bulletin de la Société Chimique de France, 22 (1874), 337-347; I. van't Hoff "Sur les formules de structure dans l'espace" (trad.), Archives Nérlandais des Sciences Exactes et Naturelles, 9 (1874), 445-454.

7 A. Wurtz, "On oxide of ethylene, considered as a link between organic and mineral chemistry", J. Chem. Soc., 15 (1862), 387-406, 387

${ }^{8}$ Vallery Radot (edit.), Oeuvres de Pasteur (Paris, 1922. 1939), 1, 345-350:360-365; 369-386.

9 Tanto Pasteur como vários dos seus discípulos competiram para lugares alocados à química no ensino superior.

10 Nesta discussão teve algum relevo o facto dos métodos franceses de produção do vinagre diferirem dos métodos alemàes.

11 De todas as experiências de Pasteur sobre a geração es. pontânea as que terăo ficado mais famosas pela sua simplicidade foram aquelas em que usou um balão cujo gargalo tinha a forma de pescoço de cisne. Depois de ter preparado uma série destes balôes onde introduzira água açucarada contendo levedura de cerveja. Pasteur alongou esses garga. los de vidro (por aquecimento) por forma a ficarem muito estreitos e encurvados de várias maneiras, mas deixando as extremidades de pequenissimo diámetro abertas. Sem selar os balōes, submeteu alguns a uma fervura durante alguns minutos, deixando outros de lado para servir de controlo. Todos os balóes foram expostos ao ar durante dois ou três dias, mas só os que năo foram aquecidos mostraram a presença de microrganismos. Além disso, se o gargalo dos balō. es fervidos fosse cortado numa região mais próxima do balão propriamente dito, então apareceriam germes ao fim de alguns dias. Pasteur concluiu que as sinuosidades e as inclinaçōes dos gargalos em forma de pescoço de cisne protegiam os liquidos da contaminaçâo e da proliferação de microrganismos porque retinham as poeiras e os micróbios do ar. Vallery-Radot, op. cit. (8), II 260-261. Os artigos de Pasteur sobre a geração espontânea (1860-1870), incluindo os referentes às várias controvérsias foram reunidos por Vallery-Radot (edit.), Ibid., II.

\section{Vallery-Radot (edit.), op,cit. (8), II. 109.}

13 Pouchet nas suas contra-experiências usava infusões de feno que continham micróbios resistentes ao calor, cuja existência era desconhecida na altura.

14 Por esta razão veio a ter um debate com o britânico Chariton Brian nos anos 70. Só com o trabalho de Ferdinand Cohn e John Tyndall é que se reconheceu a existência de micróbios resistentes ao calor.

15 As polémicas mais famosas de Pasteur tiveram como seus oponentes Liebig, Frémy, Oscar Brefeld, Moritz Traube e Trécul no que se refere à fermentação; no que respeita à geraçāo espontânea com Pouchet (1860)s) e Charlton Brian (1870s)

${ }_{16}$ Durante o debate entre Pasteur e Liebig sobre a fermentação Pasteur acusou os seus compatriotas Frémy e Trécul de serem anti-patrióticos: estavam a defender uma "teoria alemã" (a de Liebig) contra uma "teoria francesa". Vallery Radot (edit.), op. cit. (8), II, 379, 396.

\section{Farley e Geison, op. cit. (3).}

$18 \mathrm{O}$ Imperador Napolāo III e a Imperatriz Eugénie visitavam e eram visitados com regularidade por Pasteur que thes dedicou algumas das suas obras.

19 E. Duclaux, Pasteur, l'histoire d'un esprit, (Paris, 1896), 461.

20 Vallery-Radot (edit.), op. cit. (8), I, 376.

21 Também outros savants. Nomedamente o químico Henri Sainte-Claire Deville (1818-1881), foi financiado por verbas pessoais do Imperador, através da mediação de Dumas, em investigações que serviam objectivos económicos e políticos do Segundo Império como foi o caso da obtenção do alumínio por processos mais eficientes.

22 Pasteur terá dito para consolar a sua negligenciada muIher que haveria de "conduzi-la à posteridade". Vallery-
Radot (edit.), Correspondance de Pasteur, 1840-1895. (Paris,1951), 1, 228. Ver também carta de Marie Pasteur a filha escrita em 1884, onde diz o seguinte:"Teu pai sempre muito atarefado, mal me fala, dorme pouco, levanta-se de madrugada. Em suma, continua a levar a mesma vida de sempre desde há 35 anos", Ibid., III, 418.

${ }^{23} \mathrm{~L}$. Pasteur, "Quelques réflexions sur la science en France", in Vallery-Radot (edit.), op. cit. (8), VII, 199-221.

$24 \mathrm{Na}$ correspondêncía de Pasteur abundam referências política académica e pedidos de apoio aos seus patronos.

25 A. Cunnigham; N. lardine (edit.) Romanticism and the Sciences, (Cambridge, 1991); W. Farrar, "Science and the German university system, 1790-1850", in M. Crosland (edit.) The emergence of science in Western Europe, (London. 1975), 179-192.

26 Enquanto nos Estados Germânicos a formaçào de investigadores e a preparação de doutoramentos nas escolas de in vestigação eram concebidos como um prolongamento da formaçào superior com vista a uma especializaçẫo e a uma posterior profissionalização, em França era entendido como uma etapa inicial dentro da profissão. Contratavam-se assitentes para lugares subalternos de ensino e só depois, mas não obrigatoriamente, estes poderiam ser treinados como investigadores, in Carneiro, op. cit. (6), 1-72.

27 Citado por Dubos, op. cit. (1), 60 .

${ }^{28}$ Duclaux, op. cit, (19), 137

29 Citado em várias fontes. Ver Dubos, op. cit., (19), 60

30 Pasteur ficou escandalizado quando Ihe disseram que Grancher, um médico que colaborou nas investigaçôes sobre a raiva, tinha no seu laboratório dois sofás e uma cadeira de baloiço. Dubos, op. cit., (19), 62.

31 De entre os discipulos de Pasteur, a maior parte deles treinados por Duclaux e Roux, encontravam-se: Raulin, o seu primeiro agrégé-préparateur na Ecole Normale, Viala, Reboud, Fernbach, Chailloux, Borrel, Joubert, Calmette, Marnier, Loir, Strauss, van Thiegen, Metchnikoff, Wasserzug e tantos outros.

32 A prática francesa contrastava assim com o procedimento alemão, na medida em que nos laboratórios alemães os jovens investigadores e assistentes eram encorajados desde muito cedo a produzir contribuiçōes individuais e originais, assumindo os autores completamente a responsabilidade do que era publicado. No entanto, esta indepêndencia e incentivo à criatividade e responsabilidade individual, nào siginificava que os trabalhos não estivessem integrados num programa de investigação mais vasto liderado pelo chefe de escola, nem excluia que, tanto os colegas de laboratório como o mestre, tivessem um conhecimento mútuo dos trabalhos em curso, através de seminários regulares que foram, eles próprios, uma criaçào alemã. Liebig, por exemplo criticava Dumas por assinar os artigos dos seus estudantes de investigaçâo porque além de denotar uma atitude paternalista, algumas vezes subscreveu erros e incorreç̧ōes da exclusiva responsabilidade dos seus discípulos, I. B. Morrell, "The chemist's breeders: the research schools of Liebig and Thomas Thomson", Ambix, 19 (1982), 363-381; L, Klosterman,"A research school of chemistry in the nineteenth-century: Jean Baptiste Dumas and his research students", Annals of Science, 42 (1985), 1-80.

33 E. Duclaux, "Le laboratoire de M. Pasteur" in Ecole Normale Supérieure. Livre du Centenaire, 1795-1895, (Paris. 
$39 \mathrm{H}$. W. Paul, The Sorcerer's apprentice. The French scientist's image of German Science, 1840-1919, (Gainsville, 1972).

"Mas se Pasteur se fazia ouvir de bom grado por orelhas amigas, tinha a epiderme sensivel face às críticas." in Duclaux, op. cit. (19), 461

35 D. G. Charlton, Positivist thought in France during the Second Empire, 1852-1870, (Oxford, 1959); T. N. Clark, Prophets and patrons: the French university and the emergence of social sciences, (Cambridge, Mass., 1973); G. Motzkin, "The Catholic response to secularisation and the rise of the history of science as a discipline", Science in Context, 2 (1989), 203-226.

$36 \mathrm{~V}$. Glachant, "Pasteur disciplinaire: un incident à l'Ecole normale supérieure (Novembre 1864)", Revue universitaire. 47 (1938), 97-104; Vallery-Radot, Pasteur inconnu. (Paris,1954), 36-58 e Vallery-Radot (edit.) op. cit. (22), II, $136-142,332-339$.

${ }^{37}$ L. Pasteur, "Suppression du cumul dans l'enseignement des sciences physiques et naturelles (1868)" in ValleryRadot (edit.), op. cit. (8), VII, 205-221.

38 Por exemplo, Henri Sainte-Claire Deville foi suppléant de Dumas na Sorbonne, durante 13 anos (1853-1866), devido aos numerosos cargos políticos e administrativos deste.
40 Pasteur, "Pourquoi la France n'a pas trouvé d'hommes supérieures au moment du péril", Revue Scientifique, [2], 4 (1871), 73-77.

${ }^{41} \mathrm{~A}$ autonomia universitária bem como o sistema de organização das universidades alemãs era altamente valorizado pelos homens de ciência de além Reno como Helmoltz. cuios pontos de vista a este respeito foram alvo de uma traduçāo para francês. H. Helmoltz, "La liberté académique dans les universités allemandes", Revue Scientifique, 14 (1878), 813-820.

42 Esta era a posição do químico alsaciano Adolphe Wurt: (1813-1884) e de muitos membros da sua escola de investigaçào. A. Wurtz, Les hautes études dans les universités allemandes, (Paris, 1870).

${ }^{43} \mathrm{~L}$. Pasteur, "Quelques réflexions sur la science en France. Les laboratoires", in Vallery-Radot (edit.), op. cit. (8), VII, 200.

44 lbid

45 Latour, op cit. (3).
46 Pasteur viveu num período agitado da vida Francesa, que afectou de forma particular o mundo intelectual, nomeadamente no que se refere ao debate entre materialismo e espiritualismo. Este debate foi despoletado por um lado pela crescente influência positivista, e por outro pela bula de 1864 (Syllabus) de Pio IX que reclamava para a Igreja Católica o exclusivo em matéria de educação. Se a vigilância, e por vezes a perseguição, exercida pelos sectores ca. tólicos sobre livre-pensadores, positivistas, materialistas, socialistas utópicos etc., foi um facto no sistema universitário francês também é verdade, que durante a Terceira República, os sectores positivistas exerceram idêntico controlo e vigilância sobre católicos, receando a sua influência. O problema era o da compatibilidade entre ciência e religião. Sendo Pasteur um católico fervoroso e um anti-positivista ferranho, e possuindo um discurso patriótico pleno de alusôes aos valores cristãos, prestou-se a um aproveitamento não isento de algum oportunismo, por parte de sectores da Igreja Católica. Assim, foi convertido num símbolo da conciliação entre ciência e religião e, nomedamante, o seu biógrafo d'Eschevannes descreve-o com atributos de santidade, chegando a comparar a fisionomia de Pasteur com a de São Vicente de Paulo. Ver J. H. Brooke, Science and religion. Some historical perspectives, (Cambridge, 1991), 297 e C. d'Eschevannes, Pasteur, sa vie, son oeuvre, sa foi, (Paris, 1934).

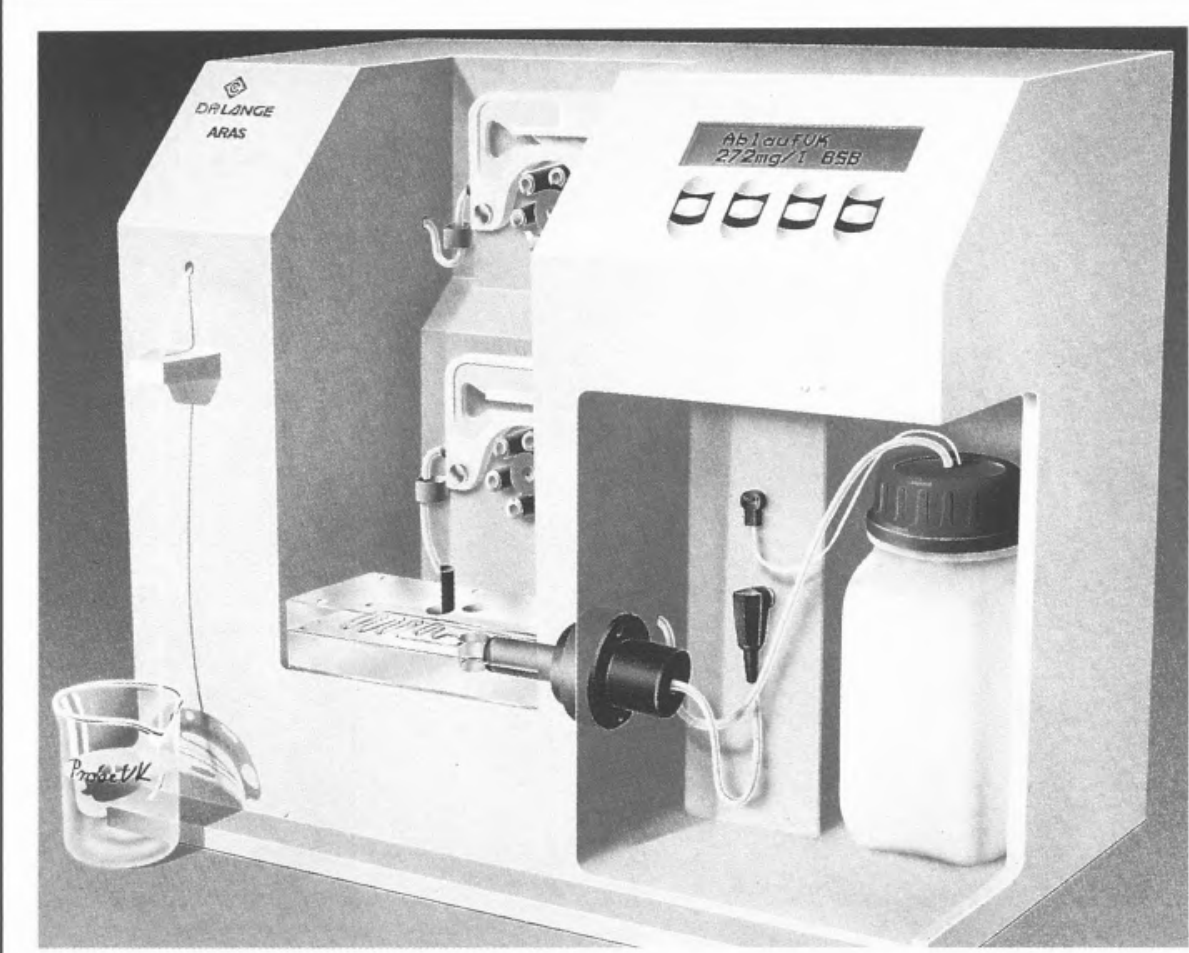

ARAS

ANÁLISE

BOD/CBO
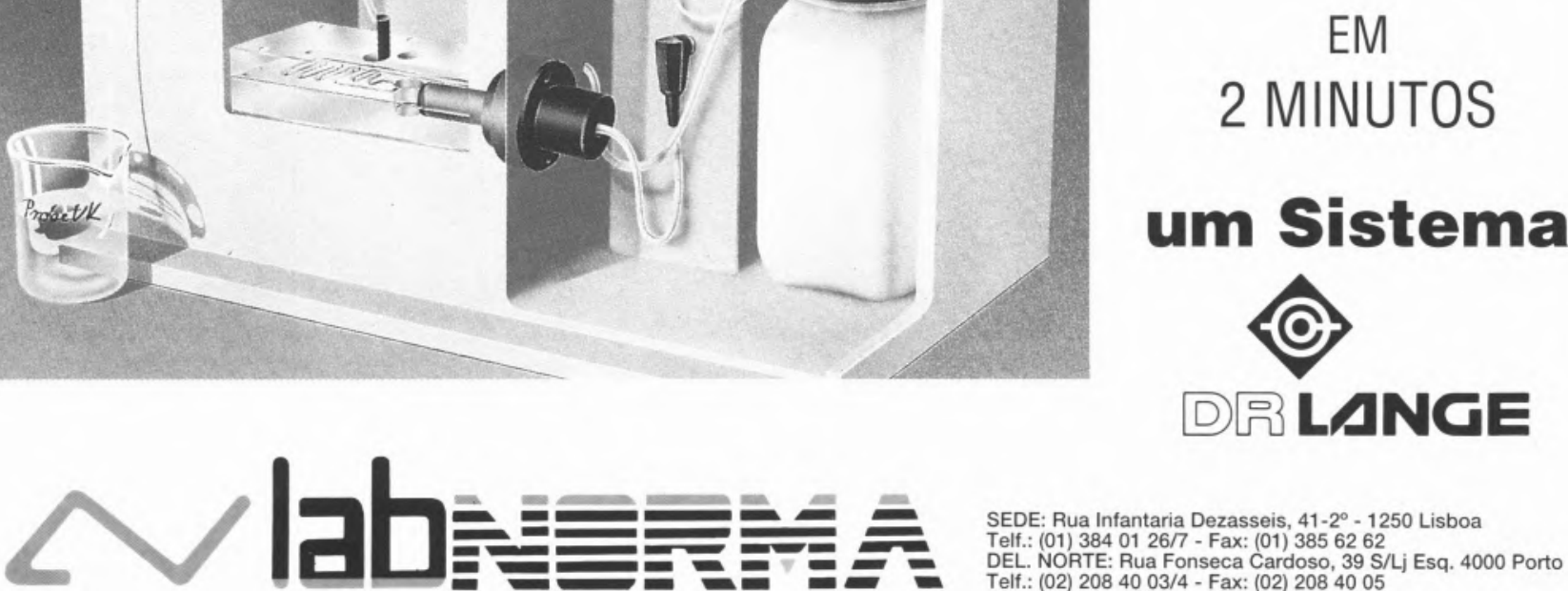

SEDE: Rua Infantaria Dezasseis, $41-2^{\circ}-1250$ Lisboa

Telf.: (01) 38401 26/7 - Fax: (01) 3856262

DEL. NORTE: Rua Fonseca Cardoso, 39 S/Lj Esq. 4000 Porto

Equipamento de controlo de qualidade e investigação, Ida. 